\title{
Bending, Lifting and Climbing
}

\section{Bending}

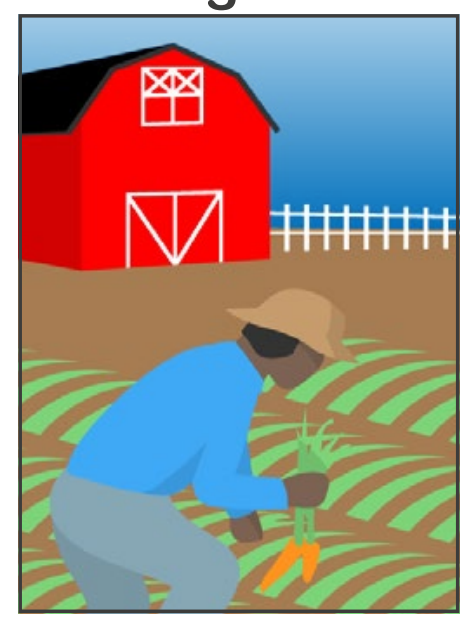

\section{Lifting}

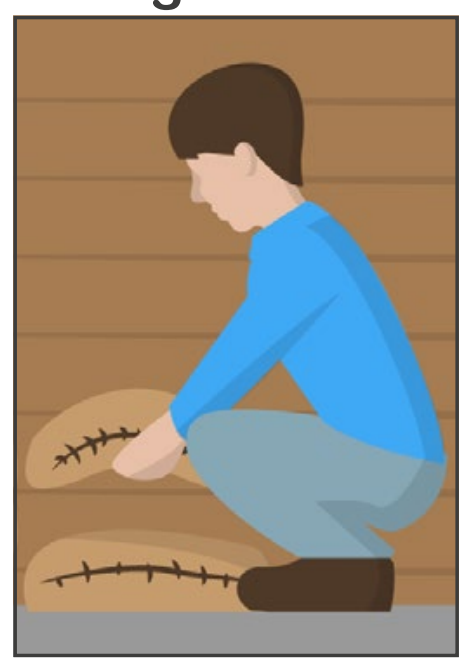

\section{Climbing}

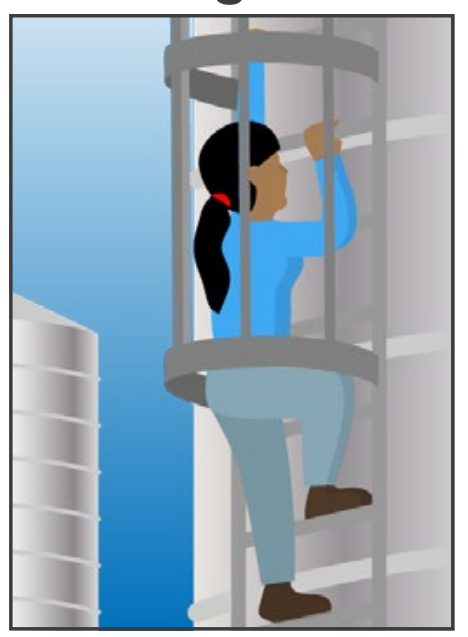

- Avoid loose clothing, clothes with strings, tie back long hair

- Perform warm-up exercises

- Bend safely, using these steps:

1. Maintain good back posture; raise and lower body with legs

2. Stand with feet shoulder-width apart, one foot slightly in front of the other

3. Keep back straight, hold in stomach muscles

4. Move down to a squatting position using your leg muscles

5. Shift from leg to leg when squatting, keeping body balanced

6. Keep your body straight; turn feet and arms, not back, to reach for objects

7. Do not stay in any one position for more than a few minutes

8. If lifting is included in task, use proper lifting techniques
- Avoid loose clothing, clothes with strings, tie back long hair

- Perform warm-up exercises

- Determine object weighs less than $25 \%$ of body weight; can carry it without straining

- Access object without obstruction

- Lift objects safely, using these steps

1. Stand close to the object

2. Spread feet wide to straddle the object

3. Squat, bending knees and hips

4. Keep head up and your back straight

5. Hold in stomach muscles

6. Lift using leg muscles, slowly and steadily

7. Keep the load close to body

8. Turn feet, not back, in the direction you are going

- Avoid loose clothing, clothes with strings, tie back long hair

- Perform warm-up exercises

- Climb safely, using these steps

1. Check that ladder is safely set

2. Grasp alternate rungs and take first step

3. Pause and think about whether or not the ladder feels stable

4. Climb up, keeping feet and hips within sides of ladder frame

5. Always maintain three contact points, for example, two hands and one foot

6. Keep head up and back straight

7. Concentrate on the climbing process

8. Do not climb beyne the third rung from the top

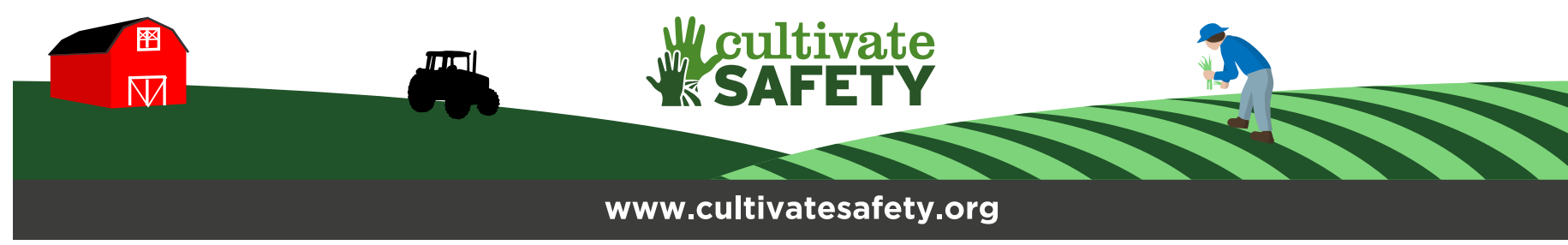

